\title{
Berifitignugen.
}

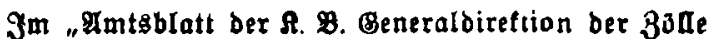
und indiretten Steuern* 1910, S. 427 开. iit cine Drud: fehlerberidtigung zu ben 2 usfügrungsbejtimmungen er: phienen. Die bort unter Biff. 1-8, 15-16 aufgefürten Berbefferungen find in biefer Yug gabe nod mährend bes Drufes angebraft worben. Mtuiter 7 und 21 find in

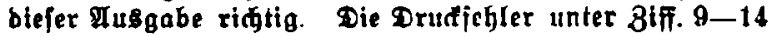
wollen wie folgt verbejiert werben:

1. (9.) In Mufter $5 \mathrm{ift}$ im Sopfe ber Spalten 5 und 6

\section{Beitere Beridtignug:}

Dufter 7 und 21 find riditg bis auf biefe Berbellerungen:

In $\mathfrak{M} u$ ite 7 (\$. 114) mus es im Ropje ber Spalte 7 ftatt $96 f .5$, Abf. 3* geiben.

In $\mathfrak{M}$ u fter 21 (ङ. 139/140) fallen in 3.1 ber Intleitung bie WOrte $_{\text {"nad }}$ ghufter 24 unb ber bajelbit gegebenen Cebrautganleltung" weg.

In 3. 7 ebenda find bie Borte innexhalb 3 Tagen au erfeben burd, am 1. auf ben Biertel.

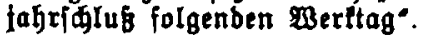

In Spalte 3 (S. 2 bes Plujters) find bie $\mathfrak{M o r t e}$ "bejw. b. Einfdreibbuds" und in Spalte 5 ift die Btteripalte ju ftrelden. 